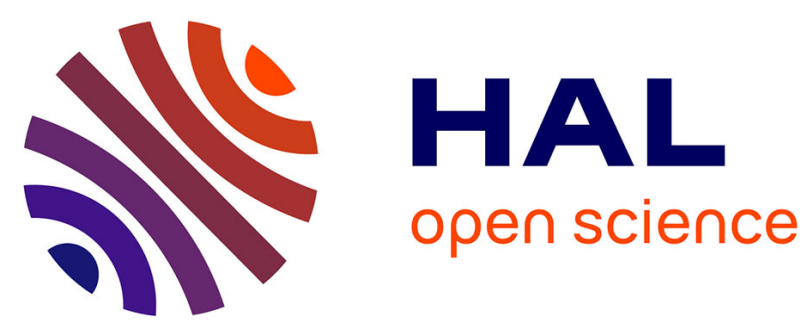

\title{
Two successive slow slip events evidenced in 2009-2010 by a dense GPS network in Guerrero, Mexico
}

\author{
Andrea Walpersdorf, Nathalie Cotte, Vladimir Kostoglodov, Mathilde \\ Vergnolle, Mathilde Radiguet, José Antonio Santiago, Michel Campillo
}

\section{- To cite this version:}

Andrea Walpersdorf, Nathalie Cotte, Vladimir Kostoglodov, Mathilde Vergnolle, Mathilde Radiguet, et al.. Two successive slow slip events evidenced in 2009-2010 by a dense GPS network in Guerrero, Mexico. Geophysical Research Letters, 2011, 38, pp.L15307. 10.1029/2011GL048124 . hal-00620540

\section{HAL Id: hal-00620540 \\ https://hal.science/hal-00620540}

Submitted on 20 May 2021

HAL is a multi-disciplinary open access archive for the deposit and dissemination of scientific research documents, whether they are published or not. The documents may come from teaching and research institutions in France or abroad, or from public or private research centers.
L'archive ouverte pluridisciplinaire HAL, est destinée au dépôt et à la diffusion de documents scientifiques de niveau recherche, publiés ou non, émanant des établissements d'enseignement et de recherche français ou étrangers, des laboratoires publics ou privés. 


\title{
Two successive slow slip events evidenced in 2009-2010 by a dense GPS network in Guerrero, Mexico
}

\author{
Andrea Walpersdorf, ${ }^{1}$ Nathalie Cotte, ${ }^{1}$ Vladimir Kostoglodov, ${ }^{2}$ Mathilde Vergnolle, ${ }^{1,3}$ \\ Mathilde Radiguet, ${ }^{1}$ José Antonio Santiago, $^{2}$ and Michel Campillo ${ }^{1}$ \\ Received 12 May 2011; revised 27 June 2011; accepted 28 June 2011; published 9 August 2011.
}

[1] A large slow slip event (SSE) had been expected for the Guerrero gap for 2010. It was actually observed with an onset in July 2009. Comparison with the preceding large SSEs, which occurred in 2002 and 2006, highlights both persistent characteristics of the Guerrero SSEs (e.g. the localization of slip in the seismogenic part of the subduction interface), and also particularities of the 2009/2010 event (namely two distinct slip patches on the fault interface moving consecutively). The long GPS time series and the density of the GPS network provide evidence that the Guerrero SSEs, like classical earthquakes, have complex features. Despite having very short and relatively regular repeat times ( $\sim 4 \mathrm{yr})$, Guerrero SSEs appear aperiodic. A shorter loading time before the 2009/2010 event than before the 2006 SSE seems to produce consistently reduced surface displacements for a group of stations in a core zone. Citation: Walpersdorf, A., N. Cotte, V. Kostoglodov, M. Vergnolle, M. Radiguet, J. Antonio Santiago, and M. Campillo (2011), Two successive slow slip events evidenced in 2009-2010 by a dense GPS network in Guerrero, Mexico, Geophys. Res. Lett., 38, L15307, doi:10.1029/2011GL048124.

\section{Introduction}

[2] The world's largest Slow Slip Events (SSE) take place on the Mexican subduction zone, in the state of Guerrero. Three slow slip events were registered by the Mexican permanent GPS network in 1998, 2002 and 2006. They reach surface displacements up to 5-6 cm, with an equivalent seismic moment of up to $\mathrm{M}=7.6$ [Lowry et al., 2001; Kostoglodov et al., 2003; Larson et al., 2004; Radiguet et al., 2011]. The very frequent and large SSEs in Mexico represent a significant contribution to the seismic cycle that was, until recently, ignored by the existing models. Moreover, the Guerrero SSEs reproduce features of the seismic cycle which, for classical earthquakes, are observable only over much longer time spans. The Guerrero subduction zone is, therefore, an exceptional natural laboratory for studying the seismic cycle and improving our capability of evaluating seismic hazard. The relatively regular occurrence of the Guerrero slip events has permitted us to calculate an average repeat time of 4-4.5 yr [Cotte et al., 2009; Vergnolle et al.,

\footnotetext{
${ }^{1}$ Institut des Sciences de la Terre, Université Joseph Fourier, CNRS UMR 5275, Grenoble, France.

${ }^{2}$ Instituto de Geofísica, Universidad Nacional Autónoma de México, México City, Mexico.

${ }^{3}$ Now at Géoazur, Université de Nice, CNRS UMR 6526, Valbonne, France.
}

Copyright 2011 by the American Geophysical Union. 0094-8276/11/2011GL048124
2010]. Since the onset of the last SSE was in April 2006, we expected the next transient event to start in 2010. In fact, the new SSE started in July 2009 and ended in September 2010. It was monitored by the continuous GPS network maintained by UNAM (Universidad Nacional Autónoma de México, Instituto de Geofisica - IG, and Servicio Sismológico Nacional - SSN). This paper aims to highlight the common characteristics and the particularities of the 2009/2010 event with respect to the preceding SSEs by examining the time evolution of the GPS positions at the surface and by using a simple dislocation model in an elastic half space [Savage, 1983] to estimate fault slip and its location on the subduction plate interface.

\section{GPS Network and Data Analysis}

[3] The 2009/2010 slow slip event was monitored over its total extent by 17 GPS stations situated in and around the Guerrero state (Figure 1). 24 other Mexican stations (19 UNAM, 5 Instituto Nacional de Estadistica y Geografia - INEGI) were not affected by the event, which indicates the spatial limits of the slow slipping patch. The Mexican stations were complimented by 36 stations from the global IGS (International GNSS Service) network in order to establish the reference frame (ITRF2008) [Altamimi et al., 2011]. This regional network was analyzed using the GAMIT/GLOBK software (version 10.35) [Herring et al., 2006], with particular attention to an up-to-date modeling of environmental effects on the GPS measurements, a strategy that has been shown to decrease noise in the time series efficiently [Vergnolle et al., 2010]. Also, as in the work of Vergnolle et al. [2010], the regional network solutions were combined with solutions from a network of globally distributed IGS stations, a strategy that helps to decrease persistent noise in the EW component, which is probably due to a lack of sufficiently close reference stations east and west of the regional network.

\section{GPS Evidence for Two Consecutive Sub-Events During the 2009/2010 SSE}

[4] The slow slip events in Mexico affect mainly the NS motion of the stations, due to the convergence of the Cocos plate with respect to the North America plate in a direction of $\sim 30^{\circ} \mathrm{N}$ and the fact that most of the slow slip motion is directed in the opposite sense to the inter-seismic loading. Therefore, to illustrate the effect of the SSE, we present in Figure 2 the north position time series of some Guerrero stations (the east and up position time series are provided in Figures S1 and S2 of the auxiliary material). ${ }^{1}$

\footnotetext{
${ }^{1}$ Auxiliary materials are available in the HTML. doi:10.1029/ 2011 GL048124.
} 

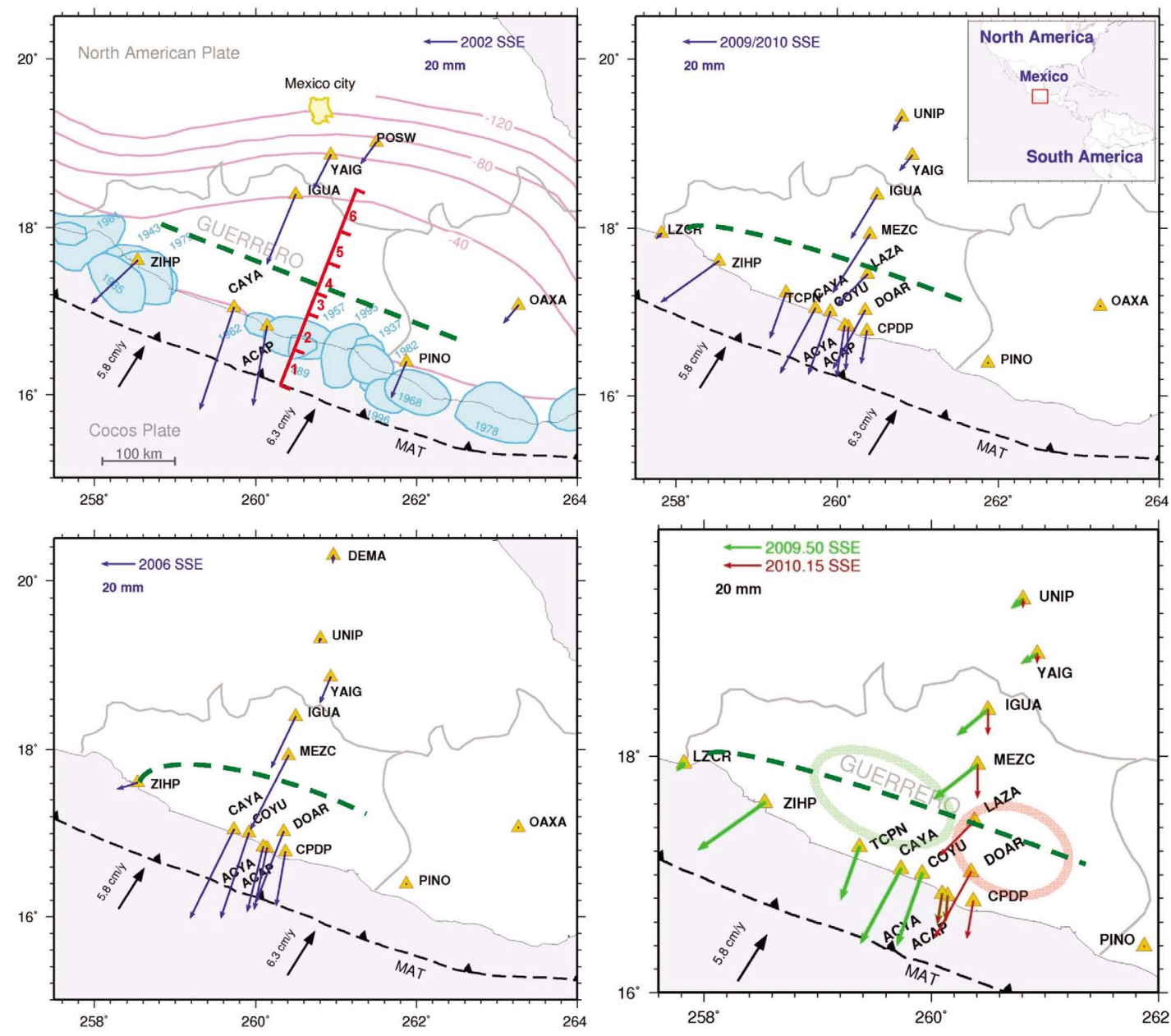

Figure 1. Network maps with total horizontal surface displacements observed by GPS during the Guerrero SSEs in (top left) 2002, (bottom left) 2006, and (top right) 2009/2010, and (bottom right) the 2009/2010 displacements split into two sub-events described in section 3. The black vectors indicate the convergence of the Cocos plate with respect to the fixed North America plate (PVEL) [DeMets et al., 2010]. In the top left graph, purple contour lines indicate the depth of the subduction interface from Franco et al. [2005], and the red bar the surface projection of the dislocation model segments. All graphs present schematically the limit between uplift and subsidence areas by the green dashed line. The surface projections of the two slip patches in 2009/2010 are shown schematically by the green (2009.5) and red (2010.15) ellipses in the bottom right graph.

[5] Figure 2 shows the steady inter-SSE displacement of the Guerrero stations with respect to ITRF2008 from the beginning of 2007 (after the end of the preceding 2006 event) until the onset of the slow slip which takes place between mid-2009 and the beginning of 2010, for different station locations. Three sets of stations can be distinguished: The first group has an onset around 2009.5 and continuous slip until $\sim 2010.5$, for the second group the onset is around 2010.15 , followed by continuous slip until $\sim 2010.5$, and a third group has an onset around 2009.5, a short interruption of slip around 2010.0 before continuing the slip until 2010.5 (Figures 2 and S1 and S2 of the auxiliary material, time series in green, red and orange, respectively). These different slip behaviors seem to be spatially correlated, the first set of stations being situated in the west of the network, the second set in the east, and the last set in the center of the network. The remarkable feature of this particular slow slip event is that the slip onsets are not progressive between 2009.5 and 2010.15 , corresponding to a migration of slip onset from an initialization point to the edges of the slipping patch, but are either close to 2009.5 or close to 2010.15, suggesting two distinct slip events. The locations of the stations of the first and the second set indicate the core zones of each of the two sub-events. Both slip events involve stations located between the two distinct slipping patches (see Figure 1, bottom right map). During the 2006 SSE, the slip onset propagated from CAYA to the SE along the coast at $1.3 \mathrm{~km} /$ day [Vergnolle et al., 2010]. In the next event, the slip onset observed at 2009.5 at CAYA station propagated to CPDP station (at a distance of $74 \mathrm{~km}$ ) in 57 days when applying the same propagation velocity. Slip onset should therefore have occured at 2009.66 at CPDP, while in fact it was not observed until 6 months later, at around 2010.15. This observation clearly suggests that the slow slip event of $2009 / 2010$ is evolving in a different way to the 2006 event.

\section{Surface Displacement and Displacement Gradient During the 2002, 2006, 2009/2010 SSEs}

[6] In this section, the total displacements observed in $2009 / 2010$ are compared to the previous SSEs. Total surface 


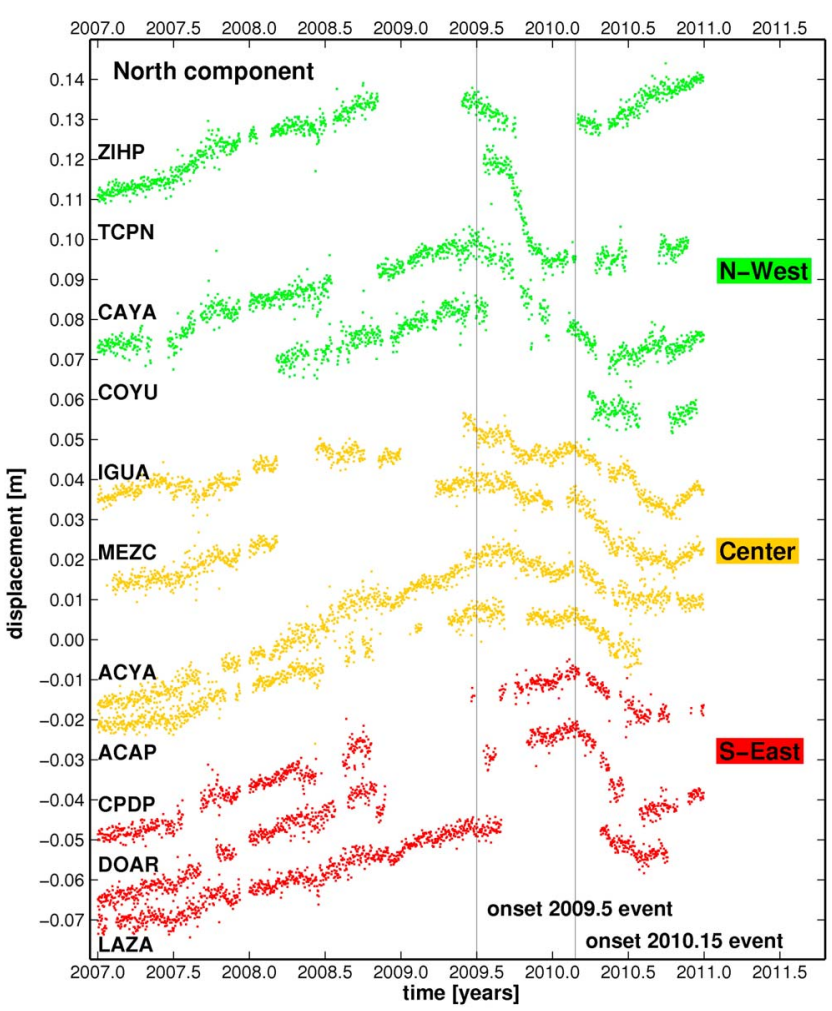

Figure 2. Time series of North components (reference ITRF2008) according to slip behavior: Stations slipping during the first sub-event in green, stations slipping during the second sub-event in red, and stations affected by both events in orange. Stations are ordered according to their approximate position along-strike (top to bottom from NW to SE).

displacements during the successive SSEs were evaluated according to Vergnolle et al. [2010]: For each position time series, the steady inter-SSE velocity was calculated over the interval 2007.0 to 2009.5 and was subtracted from the position time series. This yielded zero-slope portions during the inter-SSE intervals. The cumulative displacement during the SSE was calculated as the displacement between two successive zero-slope portions (before and after the slip event). Table S1 of the auxiliary material presents the observed motion on the three coordinates N/E/U for the Guerrero stations for the last three SSEs. In Table 1, total displacements and their variability between the three SSEs are quantified for the oldest stations. The horizontal displacement vectors are shown in Figure 1. A comparison of these three displacement fields indicates that the maximum surface displacement is decreasing from 2002 to $2009 / 2010$.

[7] There are some persistent features in the three slow slip events: Generally, the CAYA station on the Pacific coast shows the largest displacement during the slip events (66, 61 and $45 \mathrm{~mm}$ horizontal motion in 2002, 2006 and $2009 / 2010)$. There is a strong gradient in horizontal motion towards the SE. At nearby stations such as ACAP $(\sim 50 \mathrm{~km}$ to the SE), displacement is significantly smaller than at CAYA (about $20 \mathrm{~mm}$ smaller). The gradient is weaker along the direction perpendicular to the coast (NE), with horizontal displacements for example at the $120 \mathrm{~km}$ distant MEZC station that are only 10 and $2 \mathrm{~mm}$ less than CAYA in 2006 and 2009/2010. Also, the directions of motion show some patterns that seem to be repeated by the successive events, like the pronounced west component at ZIHP and the slight but persistent west component of DOAR with respect to close-by sites CPDP, ACAP and ACYA.

[8] The area of the transient surface displacement was largest during the 2002 SSE when the PINO and OAXA stations, in the Oaxaca state, and the most northern stations YAIG and POSW recorded a transient motion $(\sim 10-20 \mathrm{~mm})$ coherent with the GPS stations in Guerrero. The displacement areas of the 2006 and 2009/2010 events are more limited to the Guerrero state in their EW extent and to Mexico City in their NS extent (the UNIP station with 2 and $10 \mathrm{~mm}$ horizontal displacements in 2006 and 2009/2010).

[9] The vertical components (see Table S1 of the auxiliary material) show a coherent pattern of upward motion for the stations along the coast and downward motion for stations inland, with a transition point from up to down motion located close to station LAZA. The maximum of downward motion corresponds approximately to the location of the lower limit of the slipping patch on the subduction interface at depth [Savage, 1983]. The new station LAZA, situated between DOAR and MEZC, has been operational since the end of 2006. This station provides new, additional constraints on the down dip limit of slip on the interface during the 2009-2010 event that were not available during the preceding slip events.

[10] The three additional stations that recorded the 2009/ 2010 SSE reveal the complexity of the transient slip distribution. Different displacement amplitudes of the nearby stations at the coast (CAYA and COYU with $\sim 40 \mathrm{~mm}$ south and $\sim 40 \mathrm{~mm}$ upward motion framed by ACYA, ACAP, CPDP to the east with $25 \mathrm{~mm}$ south and $15 \mathrm{~mm}$ upward motion, and by TCPN to the west with $30 \mathrm{~mm}$ south, but more than $50 \mathrm{~mm}$ upward motion) highlight particularly large displacement gradients along the coast during the 2009/2010 event. A generally more consistent displacement distribution noted in a direction perpendicular to the coast in previous SSEs was called into question in 2009/2010 by the displacement at LAZA which was too small. This station moved only by $27 \mathrm{~mm}$ horizontally with respect to the neighboring DOAR $(41 \mathrm{~mm})$ and MEZC $(43 \mathrm{~mm})$. A particular feature of the $2009 / 2010$ SSE is that the displacement

Table 1. Total 3D Displacements During SSEs 2002, 2006 and 2009/2010 and Percentage of Variation of the 2006 and 2009/ 2010 SSEs With Respect to the Previous Event

\begin{tabular}{|c|c|c|c|c|c|}
\hline \multirow[b]{2}{*}{ Station } & \multicolumn{3}{|c|}{$\begin{array}{c}\text { Total 3D } \\
\text { Displacements }(\mathrm{mm})\end{array}$} & \multicolumn{2}{|c|}{$\begin{array}{c}\text { Variation } \\
\text { (\% of previous } \\
\text { displacements) }\end{array}$} \\
\hline & 2002 & 2006 & $2009 / 2010$ & 2006 & $2009 / 2010$ \\
\hline MEZC & & 57.5 & 52.8 & & -8 \\
\hline IGUA & 50.6 & 40.2 & 36.2 & -21 & -10 \\
\hline DOAR & & 65.9 & 57.3 & & -13 \\
\hline ACYA & & 45.3 & 35.8 & & -21 \\
\hline CAYA & 91.6 & 83.4 & 60.0 & -9 & -28 \\
\hline COYU & & 79.4 & 55.3 & & -30 \\
\hline YAIG & 25.4 & 17.6 & 11.9 & -31 & -32 \\
\hline ACAP & 56.6 & 44.8 & 29.5 & -21 & -34 \\
\hline CPDP & & 39.2 & 24.2 & & -38 \\
\hline ZIHP & 46.6 & 13.4 & 63.5 & -71 & +373 \\
\hline UNIP & & 2.5 & 12.8 & & +412 \\
\hline
\end{tabular}




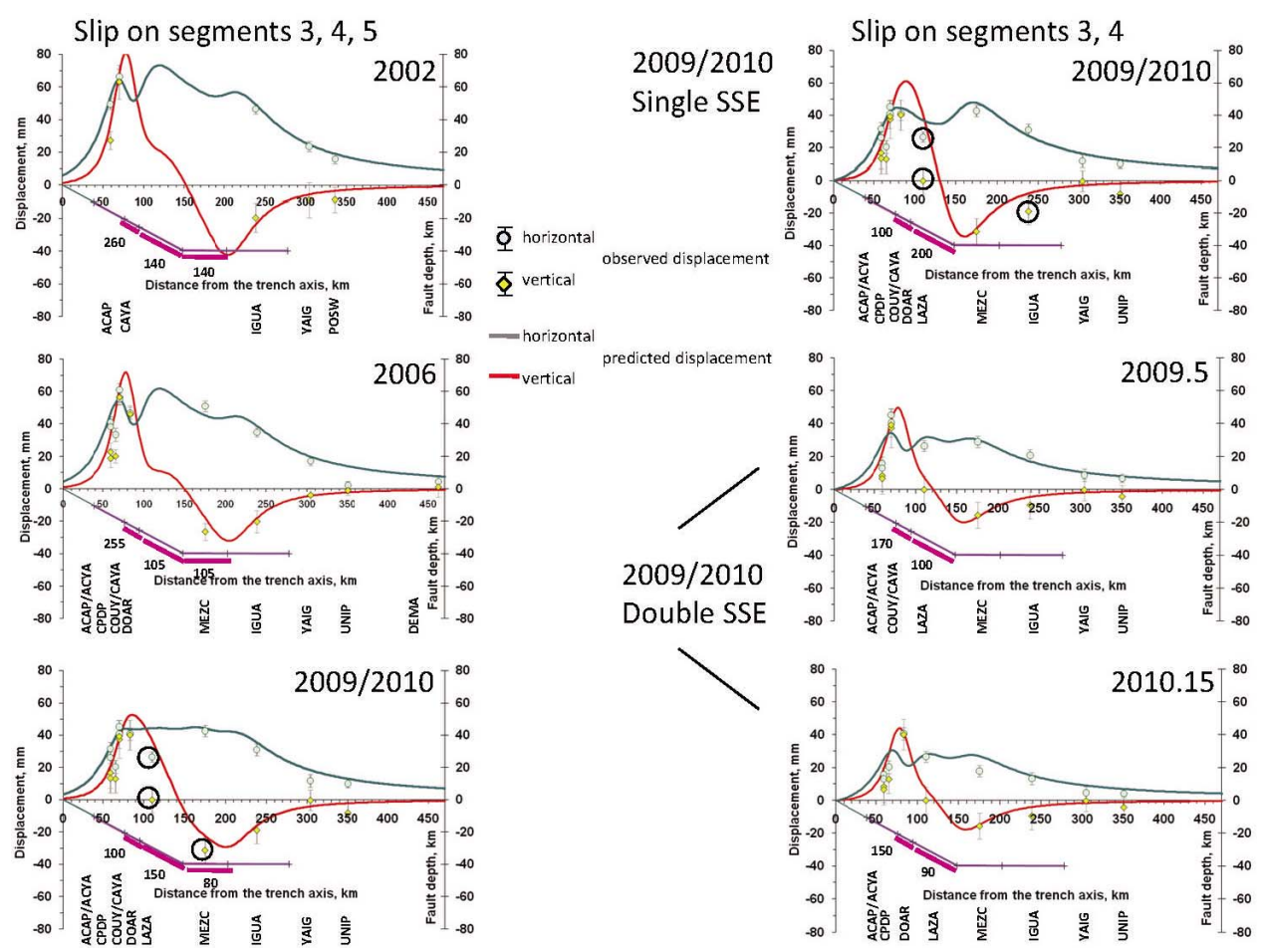

Figure 3. Dislocation models in an elastic half space. (left) Models explaining the total cumulative displacements over the three events 2002, 2006 and 2009/2010 by the dislocation on the same three segments of the subduction interface. (right) Models explaining the 2009/2010 displacements as a single slip event (top case) and as two sub-events (two bottom cases). Slip is restricted on only two segments. Slip location at depth is highlighted by the thick purple line, with the amount of slip indicated in $\mathrm{mm}$. The resulting surface deformation is shown by the grey and red lines for horizontal and vertical displacements, respectively. GPS measured displacements on the horizontal and vertical components are indicated by grey circles and yellow diamonds, respectively. Black circles indicate GPS measurements with relatively high residuals that are discussed in the text.

of the ZIHP GPS station (located on the coast at $141 \mathrm{~km}$ NW from CAYA and usually at the edge of the SSE area) reaches the same amplitude as the CAYA station $(44 \mathrm{~mm})$.

[11] Splitting up the 2009/2010 SSE into two sub-events according to the onset times and the evolution of the individual coordinate time series (single or double transient surface displacement) as presented above, results in two distinct and more homogeneous sets of displacements (Figure 1, bottom right map). In particular, the LAZA displacement amplitude now fits with the amplitudes of the surrounding stations. The west components of LAZA and DOAR correspond to that already observed in the 2006 event for DOAR and could represent a local persistent heterogeneity at the interface. The coherence of the surface displacements in two sub-events can be tested by applying elastic dislocation modeling.

\section{Modeling Slip Distribution on the Subduction Interface}

[12] We use a simple, two-dimensional, dislocation model in an elastic half space [Savage, 1983] to estimate the amount of slip on the subduction interface at depth and its distribution along a profile perpendicular to the trench [Kostoglodov et al., 2003]. The geometry of the subduction interface is derived from Kim et al. [2010]. The interface dips with an angle of $15^{\circ}$ from the trench. At $140 \mathrm{~km}$ distance from the trench, the slab becomes quasi horizontal at
$40 \mathrm{~km}$ depth. The interface is modeled by 7 segments that can slip independently (the location of the surface projections are shown in Figure 1). The first segment is connected to the trench and freely slipping (0-10 km deep). Segments 2-3 represent the "seismogenic" zone (10-25 km deep) and segments 4-6 the "transition" zone (25-40 km deep) as defined by Larson et al. [2004] and further characterized by Kostoglodov et al. [2010]. Segment 7 is usually defined as freely slipping and situated in the ductile part of the subduction zone ( $\sim 40 \mathrm{~km}$ deep). As in the work of Kostoglodov et al. [2003], the subduction interface geometry and the length of the individual segments are fixed, while slip on segments 3, 4 and 5 is varied to determine by ad-hoc forward modeling the best explanation of the observations, for the three last major SSEs.

[13] Figure 3 presents the slip distributions on the interface that fit the observed surface displacements for the three SSEs of 2002, 2006 and 2009/2010. In Figure 3 (left), the SSEs are modeled by a coherent slip on segments 3,4 and 5 , from 70 to $200 \mathrm{~km}$ from the trench and between 20 and $40 \mathrm{~km}$ depth. Maximum slip at depth is localized on segment 3 (from 70 to $100 \mathrm{~km}$ from the trench and between 20 and $25 \mathrm{~km}$ deep) in both the 2002 and the 2006 SSE models. In 2009/2010, maximum slip is localized on segment 4 (from 100 to $150 \mathrm{~km}$ from the trench) and is lower than during the previous events $(150 \mathrm{~mm}$ instead of $225 \mathrm{~mm}$ in 2006 and $240 \mathrm{~mm}$ in 2002), as expected from the lower maximum surface displacement (see also displacement 
variations in Table 1). The 2009/2010 event differs from the previous SSEs by the relatively large displacements at the inland stations MEZC and IGUA. In particular, the 2009/2010 model with slip on three segments cannot explain the large vertical motion of MEZC $(175 \mathrm{~km}$ from the trench, indicated by a circle). Moreover, new constraints are available in 2009/ 2010 with the LAZA station $(110 \mathrm{~km}$ from the trench, indicated by circles) that are also mis-modeled. The information provided by LAZA (no vertical motion at $110 \mathrm{~km}$ from the trench) suggests that the maximum of downward motion (corresponding to the lower limit of the slipping patch) is situated closer to the trench, i.e. between LAZA and MEZC rather than between MEZC and IGUA.

[14] Limiting the slip to segments 3 and 4 (Figure 3, right) and excluding slip in the transition zone of the subduction interface (segments 5 and 6) moves the maximum of downward motion toward the trench and better explains the MEZC and LAZA displacements, but leads to significant underestimation of the IGUA displacements (at $280 \mathrm{~km}$ from the trench, indicated by circles). When splitting up the 2009/ 2010 SSE into two independent sub-events starting in 2009.5 and 2010.15 (the two bottom cases in Figure 3, right), we obtain two subsets of surface displacements that remain large for stations close to the coast because either CAYA/COYU (in 2009.5) or DOAR/CPDP (in 2010.15) keep their full amplitude. However, the displacement amplitudes decrease in individual sub-events for stations inland (in particular MEZC and IGUA). As a result of this split into two subevents, the individual MEZC and IGUA displacements are more coherent with the displacements of the coastal stations, and a model with slip on segments 3 and 4 can explain most of the observed surface displacements. The LAZA station has a data gap at the end of 2009 that precludes resolving the onset time of the slow slip for this station. According to the model, the LAZA displacement can be explained $100 \%$ by both sub-events (the total LAZA displacement is shown in both graphs). But if the LAZA displacement is distributed over both events it would be overestimated by the two models. We therefore suggest that LAZA moved only during one sub-event, probably, as for stations DOAR and CPDP, in the second one. In any case, LAZA is situated in a critical zone, where the displacement is very sensitive to the lower spatial limit of the slipping patch. Its small residuals in the model 2010.15 seem to indicate that the limitation of the slipping patch to segments 3 and 4 (up to $150 \mathrm{~km}$ from the trench) is coherent with the 2D modeling of the GPS surface displacements.

[15] The identification of stations that moved only during one of the two sub-events indicates a spatial separation of the two slipping patches. This is consistent with the fact that the sum of the two sub-event slip amplitudes on segment 3 (the slipping segment closer to the coast, with 170 and $130 \mathrm{~mm}$ in 2009.5 and 2010.15 , respectively) is larger than the slip amplitude on segment 3 in a single 2009/2010 event (100 mm). Moreover, splitting up the 2009/2010 event into two sub-events results in a slip distribution that is consistent with what was observed in 2002 and 2006, locating larger slip on segment 3 rather than on segment 4 in all four events, while modeling a single 2009/2010 event inverts the magnitudes of slip on these two segments.

[16] One major observation is that all models indicate that the slow slip is required to propagate into the seismogenic, locked part (between 40 and $100 \mathrm{~km}$ from the trench and 10 to $25 \mathrm{~km}$ deep) of the subduction interface, in particular in its lower part, on segment 3 (from 70 to $100 \mathrm{~km}$ from the trench and at 20 to $25 \mathrm{~km}$ depth), to explain the surface displacements.

\section{Discussion}

[17] The 2009/2010 Guerrero SSE had been predicted to occur between April and October 2010, using an average recurrence period of $\sim 4.25$ years and the onset of the last event in April 2006 [Cotte et al., 2009; Vergnolle et al., 2010]. In fact, data obtained in 2010 showed that this SSE had already commenced in July 2009. This is significantly earlier than the predicted time, $\mathrm{T}=3.25$ years after the 2006 SSE. Therefore, the Guerrero SSEs appear to be aperiodic. However, we can check if the reduced inter-SSE interval leads to a comparably reduced amount of slip, suggesting that the SSEs are somewhat slip-predictable. With an interSSE interval reduced by $20-30 \%$ with respect to the average interval, we observe a general decrease of station displacements. The decrease varies from 8\% (MEZC) to $38 \%$ (CPDP) with respect to slip in 2006 (Table 1). The weak decrease of slip at stations IGUA and MEZC means for example that slip at these stations is relatively high in 2009/ 2010. Some extreme values in Table 1 are obtained for stations at the limits of the slipping patches (e.g. increase of ZIHP displacement by $373 \%$ ). The decrease for a number of stations in the core of Guerrero is relatively coherent with the reduced loading time, with $21-34 \%$ for ACYA, CAYA, COYU, YAIG and ACAP. There is certainly a relation between shorter loading time and less released slip, but the highly variable surface displacement reduction suggests that the slip distribution on the subduction interface in successive SSEs is too different to conclude that the Mexican SSE are slip-predictable over the entire area of the previous SSEs.

[18] A remarkable feature of the 2009/2010 event comparing it with the previous SSEs is that it comprises two sub-events separated in time by 7 months. The first event is located in the NW part of Guerrero, while the second event covers the SE part. The relation between consequent SSEs on neighboring segments of the subduction zone (e.g., Guerrero and Oaxaca SSEs) has already been discussed [e.g., Franco et al., 2005; Correa-Mora et al., 2009; Vergnolle et al., 2010], but here we present evidence for two transient events following each other shortly in adjacent but distinct regions of the same segment of the subduction interface. The denser GPS network of 2009/2010 helps to identify a more heterogeneous slip behavior of the subduction interface. Persistent slip gradients have been identified by comparing the three slip events that could be related to asperities or segmentation of the interface. One strong slip gradient is between CAYA/COYU and ACYA/ACAP stations. With the shorter loading time for the 2009/2010 event, the asperity responsible for this slip gradient seemed to act like a barrier and prohibited the slip to propagate into the eastern part of the Guerrero segment. Slip in this part then seems to have been triggered as a separate slow event 7 months later.

[19] Modeling the SSE sub-events requires slip on the downdip part of the seismogenic zone and the upper part of the transition zone (segments 3 and 4). To fit the observed surface displacements of the 2009/2010 SSE it is not necessary to apply any slip on the flat, lower part of the 
transition zone of the subduction interface (segment 5) as was done in the case of the 2002 and 2006 SSEs. Splitting up the 2009/2010 event in two sub-events reduces the residuals between models and observations, and helps in particular to explain the anomalously large displacements of inland stations MEZC and IGUA. To efficiently reduce the residuals it is necessary that the two sub-events affect different sets of stations and not twice the same ensemble of stations. We observe that the western coastal stations move in the first sub-event and the eastern coastal stations in the second. This conserves maximum displacement amplitudes close to the coast in both sub-events, while displacement amplitude is reduced inland because the total displacement of inland stations is distributed over the two events. The resulting different evolution of surface displacement along the coast perpendicular transect (with decreasing amplitudes between coast and inland) is more consistent with our dislocation model. The comparison of surface displacement and the model is therefore in favor of slip on two distinct patches on the subduction interface. Nevertheless, the denser GPS network in 2009 provides additional constraints with respect to the 2002 and 2006 events that are difficult to satisfy completely by the simple $2 \mathrm{D}$ dislocation model.

\section{Conclusions}

[20] Our 2009/2010 SSE observations indicate that some features like asperities, tectonic segmentation and barriers may be important factors in SSE nucleation and propagation, similar to classical earthquakes. The Guerrero SSEs develop slip of the order of $10-25 \mathrm{~cm}$ on very large areas of the plate interface. The equivalent moment of these events corresponds to magnitudes of $\sim 7.5$. The relatively very short average recurrence time of $\sim 4$ years have encouraged attempts at predicting future transient events [Cotte et al., 2009]. However, our detailed observation of the fourth major event in 2009/2010 does not confirm a precise recurrence interval for SSEs in Guerrero.

[21] We observe generally reduced surface displacements in the 2009/2010 event after a reduced loading time since the 2006 SSE. Nonetheless, the 2009/2010 displacement field is too complex to be described by a simple model of slip prediction.

[22] The complexity of the $2009 / 2010$ SSE requires the $4 \mathrm{D}$ inversion of the observations of this event that will corroborate our hypothesis of two separate sub-events. The relation between Guerrero SSEs and nonvolcanic tremor (NVT) has already been examined for the previous events [e.g., Payero et al., 2008; Vergnolle et al., 2010; Kostoglodov et al., 2010]. The signature of NVT data during the 2009/2010 event could provide additional credits for a discontinuous evolution of the event and is under study. For monitoring the next Guerrero SSE, which remains, nevertheless, expected to start between 2012 and 2014, six new CGPS stations have been installed in 2010 in the Guerrero area.

[23] Acknowledgments. This work could be realized thanks to the support of the SSN staff, in particular, Sarah Ivonne Franco Sanchez and Luis Edgar Rodriguez. Funding was contributed by Mexican CONACyT
(84544) and UNAM PAPIIT (IN103808) projects and by the French programs 3F (INSU), G-GAP (ANR), and PICS (CNRS). Many thanks to Felicity Lodge, who took care of the final linguistic touch of the manuscript, and to two anonymous reviewers for their constructive comments.

[24] The Editor thanks Charles Demets and an anonymous reviewer for their assistance in evaluating this paper.

\section{References}

Altamimi, Z., X. Collilieux, and L. Métivier (2011), ITRF2008: An improved solution of the international terrestrial reference frame, J. Geod., doi:10.1007/s00190-011-0444-4, in press.

Correa-Mora, F., C. DeMets, E. Cabral-Cano, O. Diaz-Molina, and B. Marquez-Azua (2009), Transient deformation in southern Mexico in 2006 and 2007: Evidence for distinct deep-slip patches beneath Guerrero and Oaxaca, Geochem. Geophys. Geosyst., 10, Q02S12, doi:10.1029/ 2008 GC002211.

Cotte, N., A. Walpersdorf, V. Kostoglodov, M. Vergnolle, J.-A. Santiago, I. Manighetti, and M. Campillo (2009), Anticipating the next large silent earthquake in Mexico, Eos Trans. AGU, 90(21), 181-182, doi:10.1029/ 2009EO210002.

DeMets, C., R. G. Gordon, and D. F. Argus (2010), Geologically current plate motions, Geophys. J. Int., 181, 1-80, doi:10.1111/j.1365246X.2009.04491.x.

Franco, S. I., V. Kostoglodov, K. M. Larson, V. C. Manea, M. Manea, and J. A. Santiago (2005), Propagation of the 2001-2002 silent earthquake and intraplate coupling in the Oaxaca subduction zone, Earth Planets Space, 57, 973-985.

Herring, T. A., R. W. King, and S. C. McClusky (2006), Introduction to GAMIT/GLOBK, release 10.3, report, Dep. of Earth Atmos. and Planet. Sci., Mass. Inst. of Technol, Cambridge.

Kim, Y., R. W. Clayton, and J. M. Jackson (2010), Geometry and seismic properties of the subducting Cocos plate in central Mexico, J. Geophys. Res., 115, B06310, doi:10.1029/2009JB006942.

Kostoglodov, V., S. K. Singh, J. A. Santiago, S. I. Franco, K. M. Larson, A. R. Lowry, and R. Bilham (2003), A large silent earthquake in the Guerrero seismic gap, Mexico, Geophys. Res. Lett., 30(15), 1807, doi:10.1029/2003GL017219.

Kostoglodov, V., A. Husker, N. M. Shapiro, J. S. Payero, M. Campillo, N. Cotte, and R. Clayton (2010), The 2006 slow slip event and nonvolcanic tremor in the Mexican subduction zone, Geophys. Res. Lett., 37, L24301, doi:10.1029/2010GL045424.

Larson, K. M., V. Kostoglodov, A. Lowry, W. Hutton, O. Sanchez, K. Hudnut, and G. Suárez (2004), Crustal deformation measurements in Guerrero, Mexico, J. Geophys. Res., 109, B04409, doi:10.1029/2003JB002843.

Lowry, A., K. M. Larson, V. Kostoglodov, and R. Bilham (2001), Transient slip in Guerrero, southern Mexico, Geophys. Res. Lett., 28, 3753-3756, doi:10.1029/2001GL013238.

Payero, J. S., V. Kostoglodov, N. Shapiro, T. Mikumo, A. Iglesias, X. PérezCampos, and R. W. Clayton (2008), Nonvolcanic tremor observed in the Mexican subduction zone, Geophys. Res. Lett., 35, L07305, doi:10.1029/ 2007 GL032877.

Radiguet, M., F. Cotton, M. Vergnolle, M. Campillo, B. Valette, V. Kostoglodov, and N. Cotte (2011), Spatial and temporal evolution of a long term slow slip event, the 2006 Guerrero Slow Slip Event, Geophys. J. Int., 184, 816-828, doi:10.1111/j.1365-246X.2010.04866.x.

Savage, J. (1983), A dislocation model of strain accumulation and release at a subduction zone, J. Geophys. Res., 88(B6), 4984-4996, doi:10.1029/ JB088iB06p04984.

Vergnolle, M., A. Walpersdorf, V. Kostoglodov, P. Tregoning, J. A. Santiago, N. Cotte, and S. I. Franco (2010), Slow slip events in Mexico revised from the processing of 11 year GPS observations, J. Geophys. Res., 115, B08403, doi:10.1029/2009JB006852.

M. Campillo, N. Cotte, M. Radiguet, and A. Walpersdorf, Institut des Sciences de la Terre, Université Joseph Fourier, CNRS UMR 5275 , Maison des Géosciences, BP 53, F-38041 Grenoble, Cedex 9, France. (awalpers@ujf-grenoble.fr)

V. Kostoglodov and J. A. Santiago, Instituto de Geofísica, Universidad Nacional Autónoma de México, Ciudad Universitaria Del. Coyoacán, México City, D. F. 04510, Mexico.

M. Vergnolle, Géoazur, Université de Nice, CNRS UMR 6526, Bât. 4, 250 rue Albert Einstein, Les Lucioles 1, Sophia Antipolis, F-06560 Valbonne, France. 